\title{
A Modified Transpalatal Arch for Correction of Bucally Placed Maxillary 2nd Molars: Non-Compliant Mechanics
}

\author{
Dr.Falguni Mehta ${ }^{1}$, Dr.Renuka Patel ${ }^{2}$, Dr.Lalit Kharadi ${ }^{3}$, Dr.Shivam Mehta ${ }^{4}$ \\ ${ }^{1}$ Head Of Department, Department of orthodontics, govt. Dental College and Hospital, Ahmedabad. \\ ${ }^{2}$ Assistant professor, Department of orthodontics, govt. Dental College and Hospital, Ahmedabad. \\ ${ }^{3} 3^{\text {rd }}$ Year Post Graduate, Department of orthodontics, govt. Dental College and Hospital, Ahmedabad. \\ ${ }^{4} 2^{\text {nd }}$ Year Post Graduate, Department of orthodontics, govt. Dental College and Hospital, Ahmedabad.
}

\begin{abstract}
The transpalatal arch (TPA) can be used as an adjunct during orthodontic treatment to help control the movement of the maxillary first molars in three dimensions including molar rotations, uprighting and maintaining transverse dimensions posteriorly. In addition it can also be used to maintain leeway space, as an additional anchorage to achieve active movement of teeth, modified for space maintenance, intrusion, etc. Here modified Transpalatal arch is used with E-chain - a non-compliant mechanics for correction of Maxillary $2^{\text {nd }}$ molar buccal crossbite.
\end{abstract}

Keywords: Buccal crossbite, Modified Transpalatal Arch, E-chain.

\section{Introduction}

After the invention of the transpalatal bar by Goshgarian, soldered or removable transpalatal bars have become a routine part of Orthodontics for anchorage purposes. The Goshgarian arch had to be classified as problematic for the movement of single tooth as the load/deflection rate was high. However, this can be utilized for anchorage purposes.

Transpalatal arch has been modified for different purposes. Low-placed transpalatal arch (TPA) is used in cases requiring molar intrusion but it may lead to indentations of the U loop on the dorsum of tongue, thus causing discomfort and irritation to the patient ${ }^{1}$.Modification using archwire sleeve over the loop of the TPA can eliminate this problem. Zachrisson (Zachrisson-type transpalatal bar [ZTPB]) and the traditional Goshgarian-type transpalatal bar (GTPB) differ in the amount and shape of the wire in the palatal loop. The ZTPB has three loops and it can be used for derotation of molars. The middle loop is larger and longer than the single round loop of the GTPB. The additional smaller loops are symmetrically positioned on either side of the middle loop. The middle loop is directed mesially, and the additional loops are directed distally ${ }^{2}$.

\section{Case report}

Here the Transpalatal arch is modified in a way that its middle loop is directed distally and two additional loops directed mesially to correct buccally placed Maxillary $2^{\text {nd }}$ molars. front teeth.

This was placed in a 13 year old male patient reported with chief complain of irregularly placed upper

Clinical examination revealed Angles'class II div 2 malocclusion, deep overbite, competent lips, decreased lower anterior facial height and convex soft tissue profile.

Teeth present $\underline{654321 \mid 123456}$

6E432 $1234 \mathrm{E} 6$

with 1 missing radiographically.(Fig 1A, 1B, 1C, 1D).

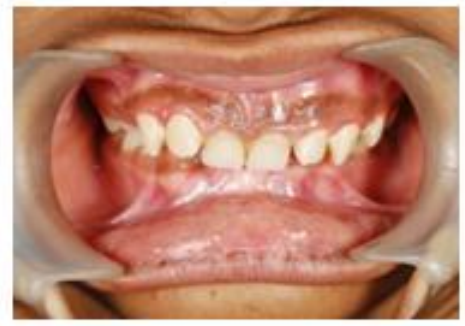

Fig. 1A

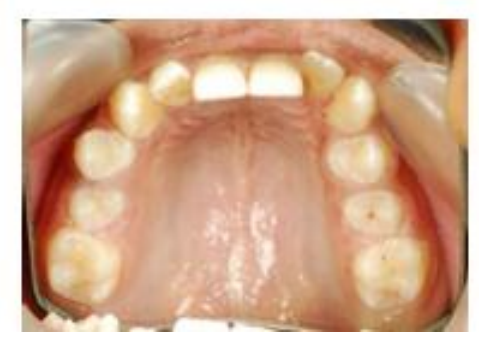

Fig. 1B

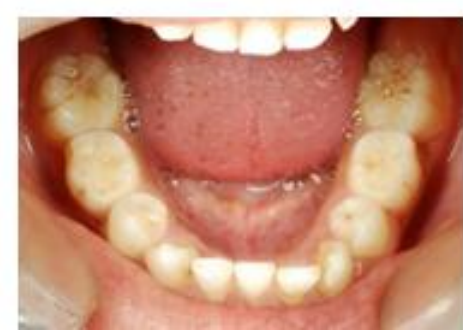

Fig. 1C 


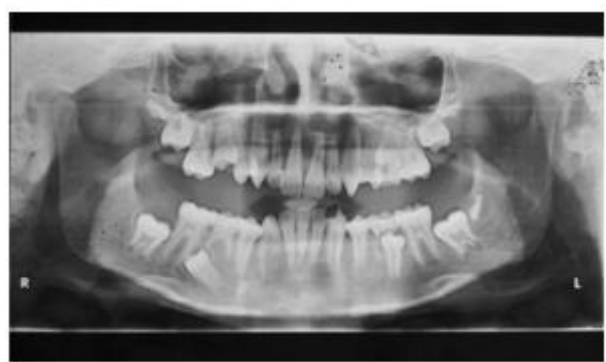

Fig. 1D

Fig. 1 A to D - Pretreatment Photos \& OPG

Treatment was started with alignment of upper anteriors by fixed mechanotherapy (Begg's Technique). After alignment of upper anteriors, fixed twin block was cemented for correction of skeletal class II.

Skeletal correction was achieved after active treatment time of 11 months, fixed twin block was removed and it was found that maxillary $2^{\text {nd }}$ molars were erupting buccally,- $8 \mathrm{~mm}$ (linear distance measured from the Mesiobuccal cusp tip of Maxillary $1^{\text {st }}$ molar to Maxillary $2^{\text {nd }}$ molar of the same side) (Fig 2A). Since the mandibular $2^{\text {nd }}$ molars had not erupted then, so interarch crossbite correcting elastics could not be given. To prevent extrusion of Maxillary $2^{\text {nd }}$ molars which can also hamper the lower $2^{\text {nd }}$ molar eruption, Modified TPA was planned to correct buccal crossbite (Figure 2A, 2B). As soon as $2^{\text {nd }}$ molars erupted, were banded with buccal tube and $\mathrm{E}$ chain was inserted from the buccal surface of maxillary $2^{\text {nd }}$ molars to the additional loop of TPA bilaterally.

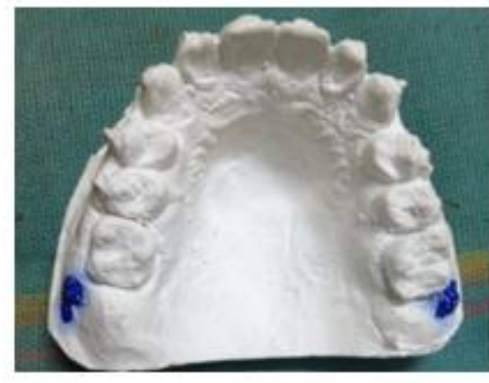

Fig. 2A

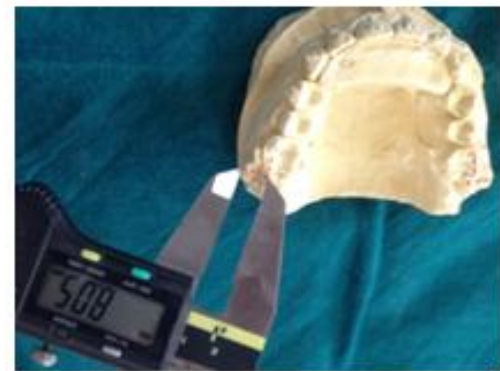

Fig. 2B

Fig. $2 \mathrm{~A}$ and $2 \mathrm{~B}-$ Maxillary $2^{\text {nd }}$ molars erupted buccally.

\section{TPA Fabrication Procedure And Clinical Application}

A Begg's single round buccal tube ( 0.036 " diameter and 0.025 " long) is welded buccally on the maxillary $1^{\text {st }}$ molar bands and impression is taken with bands and a study cast is made.

A Modified TPA is made of $1.0 \mathrm{~mm}$ hard stainless steel round wire with middle loop directed distally and two additional loops directed mesially $(4 \mathrm{~mm}$ long and $1.5 \mathrm{~mm}$ wide),symmetrically positioned on either side of the middle loop at the bisecting point of the middle third (mesiodistal) of maxillary lateral incisor and mesial surface of maxillary $1^{\text {st }}$ molar, adapted along the palatal curvature approximately $2 \mathrm{~mm}$ away from the palatal tissues. It is then soldered on the first molar bands. (Figure $3 \mathrm{~A}$ and $3 \mathrm{~B}$ )

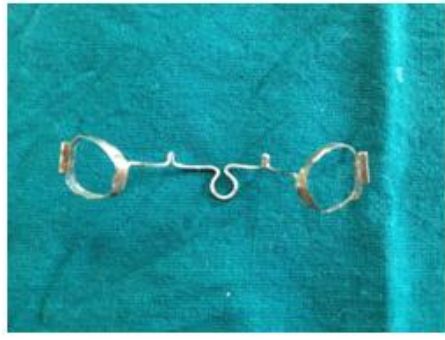

Fig. 3A

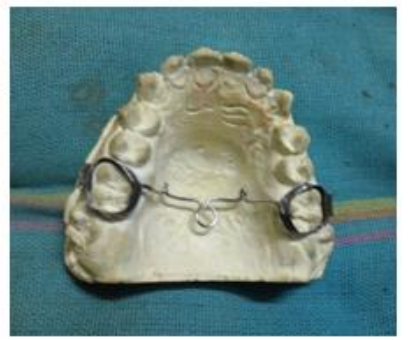

Fig. 3B

Fig. 3A and 3B - Modified TPA Assembly

This assembly is cemented on the maxillary $1^{\text {st }}$ molars.

These additional two loops on the Modified TPA is used for engaging an E-chain. 
An open long clear E-chain (Rabbit Force, Libral traders) with stretching of 8 units which exerts about 110 grams $(4 \mathrm{oz})$ of force is inserted from the buccal tube of Maxillary $2^{\text {nd }}$ molar to the loops bilaterally. Echain has to be changed every 3 weeks.

Buccally placed $2^{\text {nd }}$ molar on both the sides gets aligned in the archform within four months, so that 0.016 round plain NITI is extended to $2^{\text {nd }}$ molar to maintain the correction achieved (Figure 3Cand 3D).

Light force of 1 ounce is maintained for 3 months with prestretched E-chain to prevent relapse.

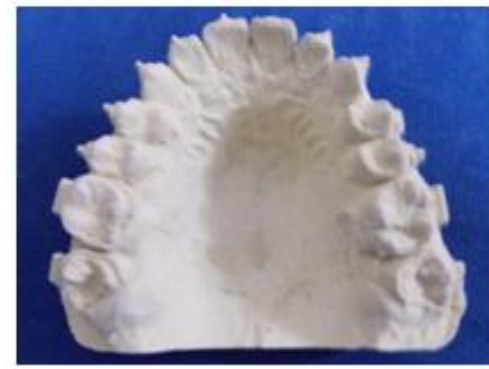

Fig. 3C

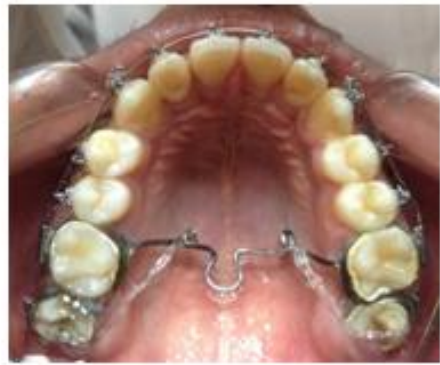

Fig. 3D

Fig. 3C and 3D - After 4 months of treatment, Maxillary $2^{\text {nd }}$ molars in arch form.

\section{Conclusion}

- Elastics are difficult to wear and require patient cooperation whereas E chain does not require patient compliance.

- An attempt to level the buccally placed maxillary $2^{\text {nd }}$ molars by using fixed orthodontic appliances and ' $S$ ' elastics leads to extrusion of teeth. It results in an opening of the mandibular plane angle, and downward and backward rotation of the mandible with worsening of the profile. Such undesirable changes can be prevented with this mechanics because E chain crosses over the occlusal surface of Maxillary $2^{\text {nd }}$ molars.

- E chain delivers predetermined intermittent force between the appointments.

- Reduced chair side time and more economical.

- Avoid surgical intervention with implant mechanics.

- It helps to apply an isolated force on the buccally placed maxillary $2^{\text {nd }}$ molars, without disturbing anchor unit and any undesired movement on the dentition.

- This kind of intraarch crossbite correction does not interfere with the physiologic eruption of teeth in the opposite arch.

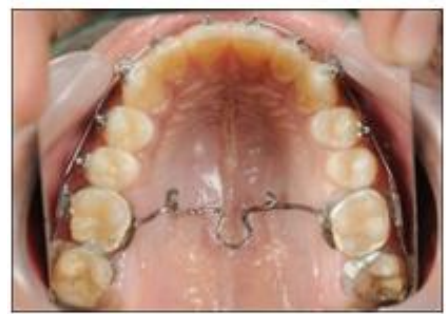

Fig. 5A

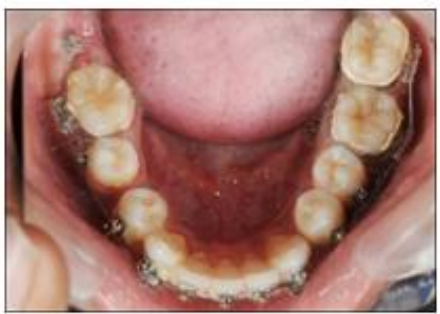

Fig. 5B

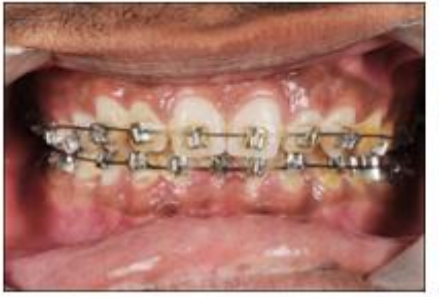

Fig. 5C

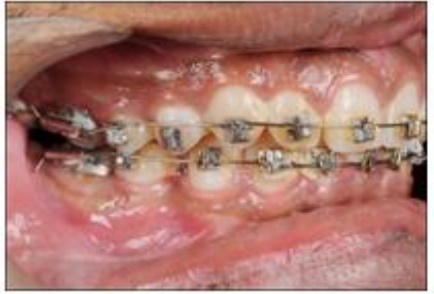

Fig. 5D

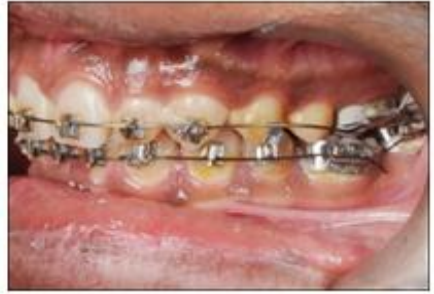

Fig. 5E

Fig. 5 A to E - Intraoral photographs after 18 months of treatment Both maxillary second molars in arch form.

\section{References}

[1]. Gupta A, Kannan S, Gupta G, Goyaliya A, Kaul A, Garg N. A Modified Transpaltal Arch With Sleeve. J IndOrthodSoc 2013;47(2):112.

[2]. ElifGündüz, A. G. Crismani, H. P. Bantleon, Klaus D. Hönigl, and Bjorn U. Zachrisson (2003) An Improved Transpalatal Bar Design. Part II. Clinical Upper Molar Derotation-Case Report. The Angle Orthodontist: June 2003, Vol. 73, No. 3, pp. 244-248.

[3]. Zablocki HL ${ }^{1}$, McNamara JA Jr, Franchi L, Baccetti T. Effect of the transpalatal arch during extraction treatment. Am J OrthodDentofacialOrthop. 2008 Jun;133(6):852-60. doi: 10.1016/j.ajodo.2006.07.031. 